\title{
Faecal nematode egg counts in Merino sheep following natural challenge
}

\author{
S.W.P. Cloete ${ }^{1 \#}$, F.H. Dreyer ${ }^{2}$ and E. du Toit ${ }^{3}$ \\ ${ }^{1}$ Elsenburg Agricultural Centre, P Bag X1, Elsenburg, 7607 \\ ${ }^{2}$ Western Cape Provincial Veterinary Laboratory, P Bag X5020, Stellenbosch, 7600 \\ ${ }^{3}$ Tygerhoek Experimental Farm, P.O. Box 25, Riviersonderend, 7520 \\ ${ }^{\#}$ Email: SchalkC@wcape.agric.za
}

\section{Introduction}

Research in other countries demonstrated genetic variation in resistance of sheep to nematode infestations (Greeff et al., 1995; Morris et al., 1996; Greeff \& Karlsson, 1999), and successful breeding programs have been reported (Woolaston \& Piper, 1996; Greeff et al., 1999). Farming with resistant strains of sheep will result in a reduced reliance on anthelmintics to control parasitic nematodes, and associated economic advantages (McEwan et al., 1995). This study reports line differences in faecal nematode egg counts in strains of Merino sheep after natural challenge, and genetic (co)variances of egg counts with other traits of economic importance.

\section{Material and Methods}

Sheep from a Merino selection experiment on the Tygerhoek experimental farm in the Southern Cape provided material for the study. The lines involved included the Fleece weight + and Control lines, the "Wet and Dry" line and the Fine wool line maintained on the experimental farm. The former two lines were established in 1968, and were described adequately in the literature (Cloete et al., 1998). Ewes in the "Wet and Dry" line have been culled since 1993 on failure to lamb or to rear at least one lamb per lambing opportunity. Rams were selected as was described by Cloete \& Scholtz (1998). A total number of 1530 progeny in these three lines were available for the period from 1995 to 1998 . The Fine wool line was descended from a similar line maintained at Cradock (Olivier et al., 1999), from which ewes were introduced to Tygerhoek during 1997. Only 59 progeny, born in 1998, were available for this line. Progeny of all lines were maintained in single flocks (separated on the basis of sex) throughout the trial. Individual pedigrees were available for all animals, except for 195 lambs born just prior to the 1997 lambing season, for which only dam identity was known. Contemporary groups (birth year, sex, dam age and birth type) were known individually. Rectal faeces samples were obtained from individual animals at 13 to 18 months of age, after drenching was withheld for at least 10 weeks. Nematode eggs in these samples were counted, using the McMaster technique, with a sensitivity of 100 eggs per gram of faeces (Van Schalkwyk et al., 1994). Other recordings included live weight and clean fleece weight at 17 months of age and fibre diameter at 15 months of age. Individual records available ranged from 1499 in the case of faecal nematode egg count to 1530 in the case of fibre diameter. The distribution of faecal nematode egg counts was skew, with a range from 0 to 13500 . The distribution could be normalized by using either the cube root or the $\log _{10}$ transformation. Based on results of Eady (1995) the cube root transformation was preferred in further analyses. The influence of fixed effects (including line differences) on the traits were estimated by least squares procedures (Harvey, 1990). The Fine wool line was excluded for this purpose, since the small number of progeny produced were representative of one year only. Fitting the appropriate fixed effects, genetic (co)variances of faecal nematode egg count with the other traits were obtained from two-trait analyses, using ASREML (Gilmour et al., 1999).

\section{Results and Discussion}

Table 1 Least square means (SE) for the traits recorded in the Fleece weight +, "Wet and Dry" and Control lines.

\begin{tabular}{lccc}
\hline & \multicolumn{3}{c}{ Line } \\
\cline { 2 - 4 } Trait & Fleece weight + & "Wet and Dry" & Control \\
\hline Faecal nematode egg counts: & $7.62^{\mathrm{a}}(0.26)$ & $6.81^{\mathrm{b}}(0.25)$ & $7.19^{\mathrm{a}, \mathrm{b}}(0.26)$ \\
Cube root transformed & 442 & 316 & 372 \\
$(\text { Mean })^{3}$ & $51.4^{\mathrm{a}}(0.4)$ & $51.3^{\mathrm{a}}(0.4)$ & $47.5^{\mathrm{b}}(0.4)$ \\
Live weight $(\mathrm{kg})$ & $4.42^{\mathrm{a}}(0.05)$ & $4.08^{\mathrm{b}}(0.04)$ & $3.70^{\mathrm{c}}(0.05)$ \\
Clean fleece weight $(\mathrm{kg})$ & $20.5(0.1)$ & $20.7(0.1)$ & $20.6(0.1)$ \\
Fibre diameter $(\mu \mathrm{m})$ &
\end{tabular}

a,b,c - Different superscripts denote significant differences $(\mathrm{P}<0.01)$ in rows 
Faecal nematode egg counts in the Fleece weight + line were higher $(\mathrm{P}<0.01)$ than in the "Wet and Dry" line, with the Control line intermediate. Means for live weight, clean fleece weight and fibre diameter were according to expectations based on the paper by Cloete et al. (1998) for the Fleece weight + and Control lines. The "Wet and Dry" line resembled the Fleece weight + line for live weight, and were intermediate for clean fleece weight. Heritability estimates for live weight, clean fleece weight and fibre diameter were consistent with a previous report (Cloete et al., 1998), and will not be presented. The heritability ( \pm SE) of faecal nematode egg count under natural challenge conditions was estimated at $0.21 \pm 0.05$. This estimate is consistent with comparable estimates in the literature (Greeff et al., 1995; Morris et al., 1996; Woolaston \& Piper, 1996; Greeff \& Karlsson, 1999; Nieuwoudt et al., 1999), ranging from 0.15 to 0.29 . Genetic correlations of faecal nematode egg counts with other traits were $-0.07 \pm 0.15$ for live weight, $0.26 \pm 0.14$ for clean fleece weight and $-0.09 \pm 0.14$ for fibre diameter. Corresponding genetic correlations in the literature were -0.08 to -0.21 for live weight, 0.10 to 0.17 for clean fleece weight and -0.06 to 0.17 for fibre diameter (Morris et al., 1996; Eady et al., 1998; Greeff \& Karlsson, 1999).

\section{Conclusions}

This study suggested that selection for resistance to parasitic nematodes should be feasible in the Merino lines studied, as was also found elsewhere (Woolaston \& Piper, 1996; Greeff et al., 1999). Although no significant difference $(\mathrm{P}<0.05)$ in faecal nematode egg counts was observed between the Fleece weight + and Control lines, it is worth mentioning that faecal nematode egg counts were found to increase in fleece weight selected Romney sheep (Williamson et al., 1994). Fleece weight selected animals, however, still maintained higher levels of production, despite heavier nematode burdens. Moreover, the study of McMillan et al. (1992) suggested the possibility of increased levels of reproduction in Romney flocks selected for an increased resistance to parasitic nematodes. These findings accorded with tendencies observed in the present study.

\section{References}

Cloete, S.W.P. et al., 1998. Aust. J. Exp. Agric. 38, 427.

Cloete, S.W.P. \& Scholtz, A.J., 1998. Aust. J. Exp. Agric. 38, 801.

Eady, S.J., 1995. Proc. Aust. Assoc. Anim Breed. Genet. 11, 79.

Eady, S.J. et al., 1998. Aust. J. Agric. Res. 49, 1201.

Gilmour, A.R. et al., 1999. ASREML - reference manual. N.S.W. Agric. Biometric Bull. No 3.

Greeff, J.C. et al., 1995. Proc. Aust. Assoc. Anim Breed. Genet. 11, 117.

Greeff, J.C. et al., 1999. Proc. Assoc. Advmnt. Anim Breed. Genet. 13, 150.

Greeff, J.C. \& Karlsson, L.J.E., 1999. Proc. Assoc. Advmnt. Anim Breed. Genet. 13, 508.

Harvey, W.R., 1990. User's guide for LSMLMW and MIXMDL. PC-2 version, Mimeograph.

McEwan, J.C. et al., 1995. Proc. Aust. Assoc. Anim Breed. Genet. 11, 70-73.

McMillan, W.H. et al., 1992. Proc. N. Z. Soc. Anim. Prod. 52, 65.

Morris, C.A. et al., 1996. N. Z. J. Agric. Res. 39, 371.

Nieuwoudt, S.W. et al., 1999. Proc. S. Afr. J. Anim. Sci. 3, 50.

Olivier, J.J. et al., 1999. Proc. Assoc. Advmnt. Anim Breed. Genet. 13, 62.

Van Schalkwyk, P.C. et al., 1994. Worm workshop: Recommendations on worm control. pp 19-21.

Williamson, J.F. et al., 1994. Proc. N. Z. Soc. Anim. Prod. $52,65$.

Woolaston, R.R. \& Piper, L.R., 1996. Anim. Sci. 62, 451. 